Check for updates

Cite this: RSC Adv., 2018, 8, 10064

\title{
Hexagonal $\mathrm{VO}_{2}$ particles: synthesis, mechanism and thermochromic properties $\dagger$
}

\author{
Hui Yan Xu, (D) ab Ke Wei Xu, ${ }^{\text {ac }}$ Fei Ma*ab and Paul K. Chu*b \\ Monoclinic vanadium dioxide $\mathrm{VO}_{2}(\mathrm{M})$ with hexagonal structure is synthesized by hydrothermal method, \\ and the phase evolution is evidenced. Interestingly, the hexagonal morphology comes into being as \\ a result of the low-energy coherent interfaces, $(21 \overline{1})_{1} / /(2 \overline{1} \overline{1})_{2}$ and $(2 \overline{1} \overline{1})_{1} / /(020)_{2}$. The size of hexagonal \\ particles is well controlled by changing the concentration of precursor solutions. Hexagonal particles \\ exhibit excellent thermochromic properties with a narrow hysteresis of $5.9^{\circ} \mathrm{C}$ and high stability. In \\ addition, the phase transition temperature can be substantially reduced down to $28^{\circ} \mathrm{C}$ by simply $\mathrm{W}$ doping.
}

Received 24th January 2018

Accepted 6th March 2018

DOI: $10.1039 / \mathrm{c} 8 \mathrm{ra00716k}$

rsc.li/rsc-advances the hydrothermal synthesis and, $\mathrm{VO}_{2}(\mathrm{~B}), \mathrm{VO}_{2}(\mathrm{~A})$ and $\mathrm{VO}_{2}$ (D) phases appeared as intermediates. To be confused, different intermediates were involved in the hydrothermal process. $\mathrm{VO}_{2}$ (B) is firstly transformed into $\mathrm{VO}_{2}(\mathrm{~A})$ and then into $\mathrm{VO}_{2}(\mathrm{R}){ }^{26}$ However, $\mathrm{VO}_{2}$ (A) does not appear in some cases. ${ }^{15}$ Here, it is demonstrated that the hydrothermal reaction process is closely related to the reaction speed that is easily controlled by changing the concentration of precursor solutions. Hexagonal structure has been evidenced extensively, but the formation mechanism is still ambiguous. Cao et al. ${ }^{27}$ proposed that it could be ascribed to the similar growth rate along the six lowenergy (201) facets, while someone suggested that it was assembled from nanobelts. In this paper, the coherent relationship between each branches of hexagonal structure is characterized, which provides deep insights into the morphology evolution of $\mathrm{VO}_{2}(\mathrm{M})$.

\section{Experimental details}

$\mathrm{VO}_{2}$ nanostructures were synthesized by the hydrothermal method using $\mathrm{V}_{2} \mathrm{O}_{5}$ as the vanadium source and oxalic acid $\left(\mathrm{H}_{2} \mathrm{C}_{2} \mathrm{O}_{4}\right)$ as a reducing agent. The filling ratio of the vessel is about $70 \%$. Firstly, oxalic acid $\left(\mathrm{H}_{2} \mathrm{C}_{2} \mathrm{O}_{4}\right)$ and $\mathrm{V}_{2} \mathrm{O}_{5}(1: 1-1: 3$ in molar) are directly added into $35 \mathrm{ml}$ deionized water at room temperature (RT), and then ammonium tungstate $\left(\left(\mathrm{NH}_{4}\right)_{10^{-}}\right.$ $\left.\mathrm{W}_{12} \mathrm{O}_{41} \cdot x \mathrm{H}_{2} \mathrm{O}\right)$ is dispersed into the above solution and stirred for 4 hours. $35 \mathrm{ml}$ of the precursor solution is transferred into a $50 \mathrm{ml}$ stainless autoclave with a Teflon liner and ultimately the autoclave is heated up to $260{ }^{\circ} \mathrm{C}$ for $1-24 \mathrm{~h}$ and then cooled in air to room temperature. The resulting black precipitate is collected and washed with distilled water and ethanol three times by centrifugation and then dried in vacuum at $60^{\circ} \mathrm{C}$ for $12 \mathrm{~h}$. The as-prepared $\mathrm{VO}_{2}$ nanostructures are ultrasonically dispersed in deionized water for $30 \mathrm{~min}$, and an appropriate quantity of silane coupling agent $\mathrm{KH}-570$ is added with ultrasonic treatment for another $30 \mathrm{~min}$. Then, polyurethane (PU, 
DISPERCOLLU54, Bayer) is added with magnetic stirring for $10 \mathrm{~min}$. Finally, the suspension is uniformly cast onto a polyethylene terephthalate (PET) substrate using an automatic coating machine and dried at $80{ }^{\circ} \mathrm{C}$ for $1 \mathrm{~min} .{ }^{30}$

The morphology of $\mathrm{VO}_{2}$ nanostructures were characterized by transmission electron microscopy (TEM) and field-emission scanning electron microscopy (FESEM, JSM-7000F). The crystal phases was determined by X-ray diffraction (GIXRD, Shimadzu XRD-7000) with $\mathrm{Cu} \mathrm{K} \mathrm{K}_{\alpha}$ radiation $(\lambda=0.154 \mathrm{~nm})$ at a fixed incident angle of $0.5^{\circ}$ and $2 \theta$ scanning rate of $8^{\circ} \mathrm{min}^{-1}$. Differential scanning calorimetry (DSC, DSC204F1, NETZSCH, Germany) were measured at $50-100{ }^{\circ} \mathrm{C}$ with a heating rate of $5{ }^{\circ} \mathrm{C} \mathrm{min} \mathrm{m}^{-1}$ under a nitrogen flow. The elemental component and chemical valence states were determined by X-ray photoelectron spectroscopy (Thermo Scientific K-Alpha, XPS). The transmittance spectra were measured in the range of 300-2200 $\mathrm{nm}$ at normal incidence using a Hitachi U-4100 spectrometer.

\section{Results and discussion}

Fig. 1 shows the XRD patterns of the samples prepared at three molar ratios $(r=1,2,3)$ of $\mathrm{H}_{2} \mathrm{C}_{2} \mathrm{O}_{4}$ to $\mathrm{V}_{2} \mathrm{O}_{5}$. Different phase evolutions, $\mathrm{VO}_{2}(\mathrm{~B}) \rightarrow \mathrm{VO}_{2}(\mathrm{~A}) \rightarrow \mathrm{VO}_{2}(\mathrm{M}), \mathrm{VO}_{2}(\mathrm{~B}) \rightarrow \mathrm{VO}_{2}(\mathrm{M})$ and $\mathrm{VO}_{2}(\mathrm{~B}) \rightarrow \mathrm{VO}_{2}(\mathrm{D}) \rightarrow \mathrm{VO}_{2}(\mathrm{M})$ are evidenced. As shown in Fig. 1a, at the reaction condition of $r=1$, only the diffraction peaks of $\mathrm{VO}_{2}$ (B) are identified for $1 \mathrm{~h}$ hydrothermal reaction. The corresponding SEM image is shown in Fig. 2a, $\mathrm{VO}_{2}$ (B) exists in the form of nanobelts with 2-4 $\mu \mathrm{m}$ long and 200-400 nm wide. The $\mathrm{VO}_{2}$ (B) phase is confirmed by the TEM images in
Fig. 3. The HRTEM image in Fig. $3 \mathrm{~b}$ shows the lattice fringe spacing of $0.353 \mathrm{~nm}$, corresponding to (110) lattice plane of monoclinic $\mathrm{VO}_{2}$ (B). As illustrated by the selected area electron diffraction (SAED) pattern in the inset of Fig. 3a, the zone axis of the reciprocal lattice is [001]. If the hydrothermal reaction time is elongated to $6 \mathrm{~h}$, new diffraction peaks corresponding to $\mathrm{VO}_{2}$ (A) and $\mathrm{VO}_{2}(\mathrm{M})$ phases appear on the XRD pattern, and a great number of nanobelts with rectangular ends emerge ${ }^{28}$ (Fig. 2b). If the reaction time is further elongated to $12 \mathrm{~h}$, the peaks of $\mathrm{VO}_{2}$ (B) vanish completely and the peak intensity of $\mathrm{VO}_{2}$ (A) and $\mathrm{VO}_{2}$ (M) increases greatly. As displayed in Fig. 2c, rectangular nanobelts and truncated nanorods coexist. Fig. 3d presents the HRTEM image of the rectangular nanobelts in Fig. 3c, the fringe spacing of $0.59 \mathrm{~nm}$ matches well with the (110) plane of tetragonal $\mathrm{VO}_{2}$ (A). According to the SEM images in Fig. 2b$\mathrm{d}$ and the XRD patterns in Fig. 1a, it can be concluded that the truncated nanorods should be $\mathrm{VO}_{2}(\mathrm{M})$. If the reaction time is elongated to $24 \mathrm{~h}$, the peaks of $\mathrm{VO}_{2}$ (A) become weakened gradually, but those of $\mathrm{VO}_{2}(\mathrm{M})$ are enhanced, that is, the growth of $\mathrm{VO}_{2}(\mathrm{M})$ rather than $\mathrm{VO}_{2}$ (A) dominates after the elimination of $\mathrm{VO}_{2}$ (B). At the reaction condition of $r=2$, no peak of $\mathrm{VO}_{2}$ (A) appears on the XRD pattern in Fig. 1b, and the size of $\mathrm{VO}_{2}$ (B) nanostructure (Fig. 2e) is reduced substantially as compared to that in Fig. 2a. Phase transition between $\mathrm{VO}_{2}(\mathrm{~B})$ and $\mathrm{VO}_{2}(\mathrm{R})$ was studied in situ by electron microscopy, ${ }^{29}$ and it was found that $\mathrm{VO}_{6}$ octahedra (Fig. S2 $\dagger$ ) in $\mathrm{VO}_{2}$ (B) abruptly broke into nanocrystallites and half of $\mathrm{VO}_{6}$ octahedra reorient into rutile structure. $\mathrm{VO}_{2}$ (B) in spheroidal morphology appears (Fig. 2g) because of severe agglomeration. At the reaction condition of


(d)

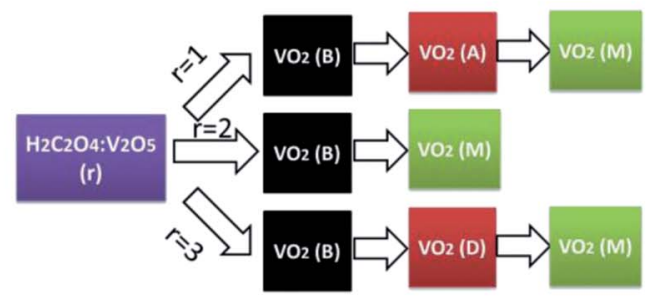

Fig. 1 XRD patterns of samples synthesized at $260{ }^{\circ} \mathrm{C}$ with different $r\left(\mathrm{H}_{2} \mathrm{C}_{2} \mathrm{O}_{4}: \mathrm{V}_{2} \mathrm{O}_{5}\right):(\mathrm{a}) r=1$, (b) $r=2$ and (c) $r=3$; (d) the diagram of phase evolution. 


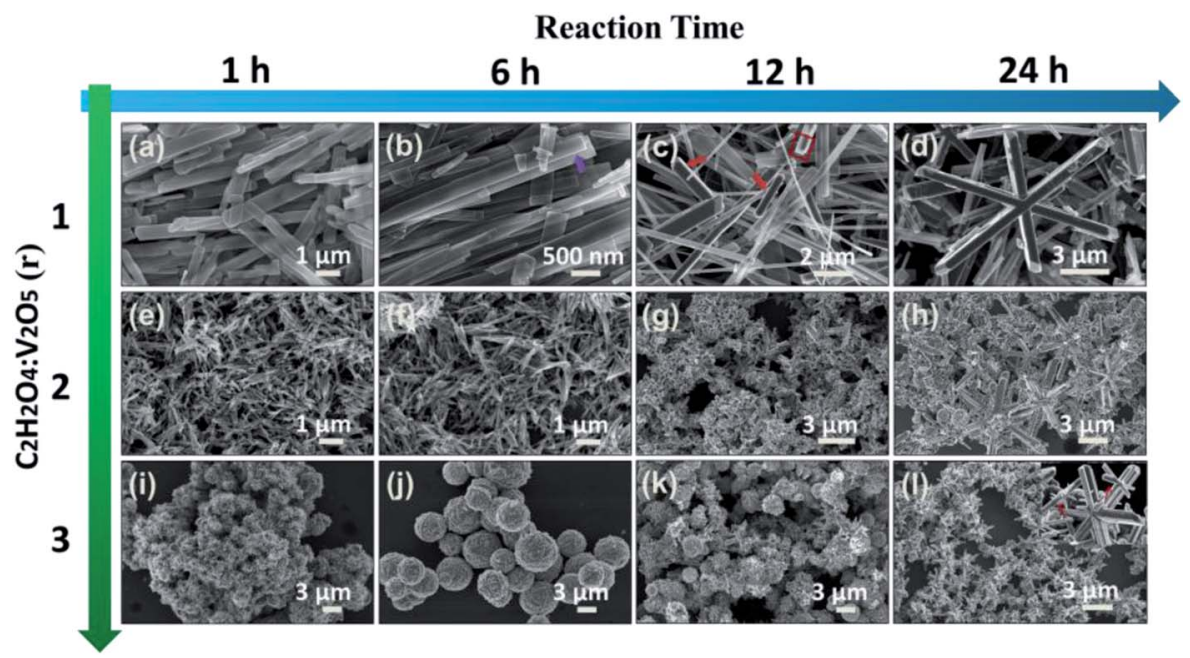

Fig. 2 SEM images of samples prepared at $260^{\circ} \mathrm{C}$ under the condition of $r\left(\mathrm{H}_{2} \mathrm{C}_{2} \mathrm{O}_{4}: \mathrm{V}_{2} \mathrm{O}_{5}\right)=1:$ (a) $1 \mathrm{~h}$, (b) $6 \mathrm{~h}$, (c) $12 \mathrm{~h}$, (d) $24 \mathrm{~h}$; $r=2:$ (e) $1 \mathrm{~h}$, (f) $6 \mathrm{~h}$, (g) $12 \mathrm{~h}$, (h) 24 h; $r=3$ : (i) $1 \mathrm{~h}$, (j) $6 \mathrm{~h}$, (k) $12 \mathrm{~h}$, (l) $24 \mathrm{~h}$.

$r=3, \mathrm{VO}_{2}$ (B) with nanorod-like or nanobelt-like morphology (Fig. 1c) aggregate into urchin-like structures to minimize the energy ${ }^{30}$ Further growth leads to the formation of larger spherelike particles as a result of Ostwald ripening (Fig. 2j). If the hydrothermal reaction time is elongated, oriented growth plays a dominant role gradually, resulting in hexagonal structure. ${ }^{31}$ According to the XRD pattern in Fig. 1c and SEM images in Fig. $2 \mathrm{j}-\mathrm{k}$, the particles are indeed $\mathrm{VO}_{2}$ (D) phase. The lattice fringes with a spacing of $0.372 \mathrm{~nm}$ corresponds to the (011) lattice plane of $\mathrm{VO}_{2}$ (D), as shown in Fig. 3f. If the ratio of $\mathrm{H}_{2}-$ $\mathrm{C}_{2} \mathrm{O}_{4}: \mathrm{V}_{2} \mathrm{O}_{5}$ is lower than 1 or higher than 3, no $\mathrm{VO}_{2}(\mathrm{M})$ appears. However, pure $\mathrm{VO}_{2}$ (A) is obtained when $r$ is slightly lower than 1 (Fig. S3†). Cao et al. prepared $\mathrm{W}$-doped hexagonal $\mathrm{VO}_{2}$ (M) via one-step hydrothermal reactions at $240{ }^{\circ} \mathrm{C}$ for 7 days, and proposed that the hexagonal morphology was assembled by the $\mathrm{VO}_{2}(\mathrm{M})$ rods along six low-index planes, ${ }^{32}$ but they did not provide us the underlying mechanism for the formation of the hexagonal morphology. Ji et al. thought that the transformation from $\mathrm{VO}_{2}(\mathrm{~A})$ to $\mathrm{VO}_{2}(\mathrm{M})$ was a resolving and re-crystallization process, and the hexagonal particles could be attributed to the electrostatic attraction. ${ }^{33}$ However, in this work, no agglomeration and melting behavior are observed during the transformation from $\mathrm{VO}_{2}(\mathrm{~A})$ into $\mathrm{VO}_{2}(\mathrm{M})$, but the ultra-long $\mathrm{VO}_{2}(\mathrm{~A})$ belts are broken into truncated $\mathrm{VO}_{2}(\mathrm{M})$ rods, and hexagonal morphology of $\mathrm{VO}_{2}(\mathrm{M})$ is formed through an epitaxial growth taking the center regions of rods as the nucleation sites [Fig. $2 \mathrm{c}$ and d].

Fig. 4 presents the TEM images of $\mathrm{VO}_{2}$ nanostructure with hexagonal morphology. The lattice spacings of $0.242,0.230$ and $0.242 \mathrm{~nm}$ in Fig. $4 \mathrm{~b}$ correspond to $(2 \overline{1} \overline{1}),(020)$ and $(21 \overline{1})$ planes of $\mathrm{VO}_{2}(\mathrm{M})$, respectively. The SAED pattern from an individual nanorod (Fig. 4d) is indexed to monoclinic $\mathrm{VO}_{2}$ with a zone axis of [102]. The diffraction pattern does not change as the electron beam is moved along the nanobelt, characteristic of singlecrystal feature. The experimental result is well consistent with the calculated SAED pattern in Fig. 4d. The SAED pattern shows that the growth is along [100] direction. As depicted in Fig. 4e, bud-like nanoparticles grow outwards from a nanorod, in which $(21 \overline{1})_{1} / /(2 \overline{1} \overline{1})_{2}$ and $(2 \overline{1} \overline{1})_{1} / /(020)_{2}$ coherent interface exist in the adjacent branches, thus small lattice distortions emerge if they are combined into a heterogeneous interface. It is demonstrated
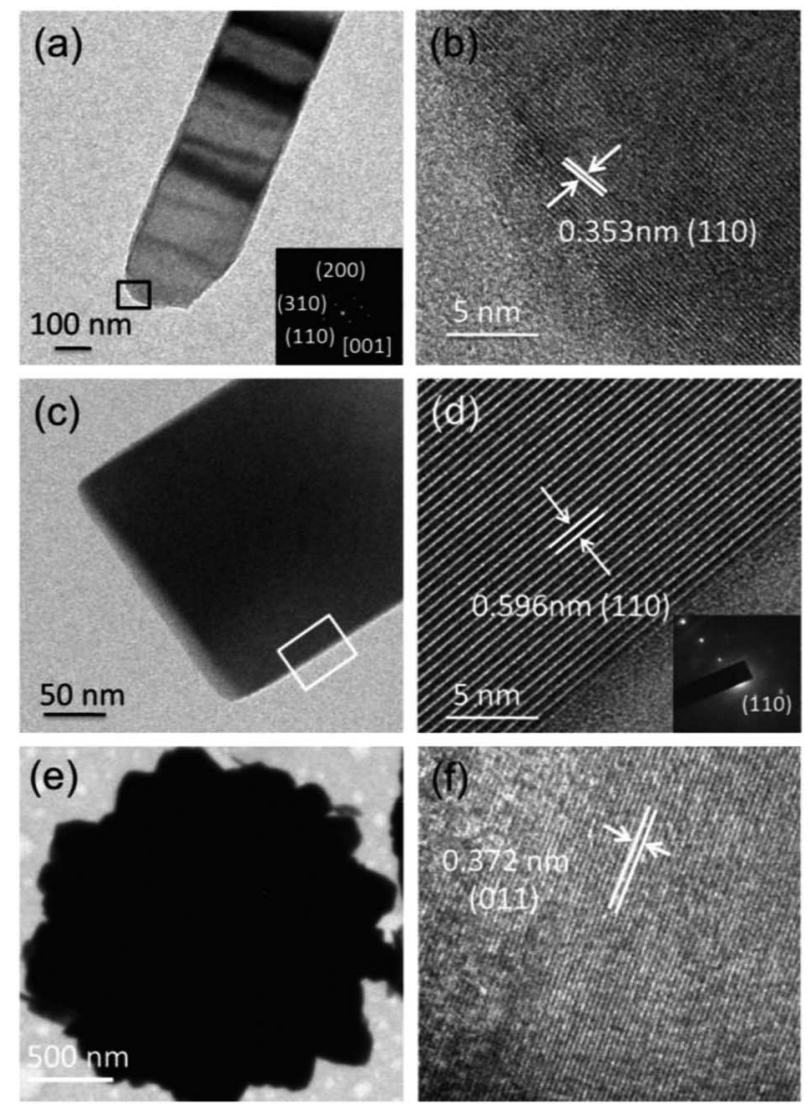

Fig. 3 (a), (c) and (e) low-resolution TEM image of $\mathrm{VO}_{2}(\mathrm{~B}), \mathrm{VO}_{2}(\mathrm{~A})$ and $\mathrm{VO}_{2}$ (D), respectively. (b), (d) and (f) corresponding to the HRTEM images. 

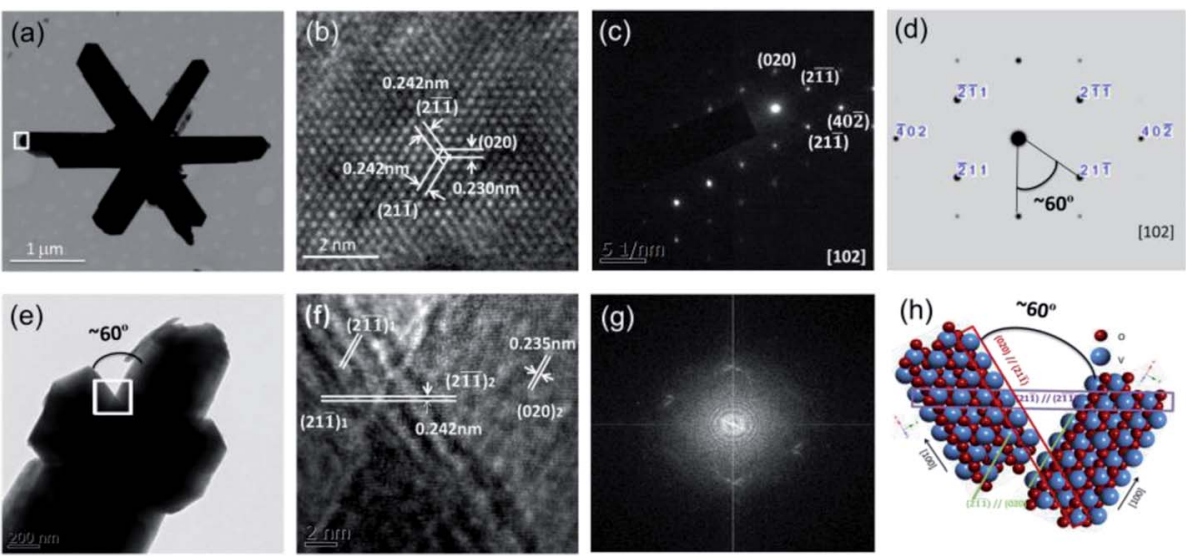

Fig. 4 (a) Low-magnification TEM images, (b) HRTEM image at the $\mathrm{VO}_{2}$ rod end, (c) SAED pattern of the particle in (b) and (d) the calculated SAED pattern from [102] zone axis, (e) low-magnification TEM image, (f) HRTEM image of the overlap region between adjacent branches, (g) the FFT pattern of the overlap region from panel (f) and (h) the atomic arrangement in panel (f).

that the angle (about $60^{\circ}$ ) between the adjacent branches is decided by the coherent interfaces. The overlapped FFT patterns in Fig. $4 \mathrm{~g}$ confirm the coherent crystalline planes between the adjacent branches, and Fig. $4 \mathrm{~h}$ schematically shows the atomic arrangement.

Fig. 5 schematically shows the evolution of $\mathrm{VO}_{2}(\mathrm{M})$ hexagonal morphology. The reaction proceeds toward the lowest energy, and promotes the oriented attachment. ${ }^{34}$ Firstly, $\mathrm{V}_{2} \mathrm{O}_{5}$ is reduced by $\mathrm{H}_{2} \mathrm{C}_{2} \mathrm{O}_{4}$ and the interphase $\mathrm{VO}_{2}(\mathrm{~B})$ is produced. As the reaction proceeds, oriented attachment or aggregation occurs spontaneously in order to minimize energy, ${ }^{35}$ thus a great number of belts (Fig. 2b) or urchin-like (Fig. 2i) structure appear. Then metastable $\mathrm{VO}_{2}$ (B) transforms into a more stable phase gradually. As aforementioned, different growth processes yield different interphases, which are dominated by nucleation rate and growth rate. $\mathrm{H}_{2} \mathrm{C}_{2} \mathrm{O}_{4}$ plays an important role in reduction rate and further affects the supersaturation. The ratio of growth rate to nucleation rate is high under low supersaturation condition and vice versa (Fig. S4 $\dagger$ ). In another word, the competition between nucleation rate and growth rate results in different morphologies, high nucleation rate results in aggregation and high growth rate leads to ultra-long nanobelts. $\mathrm{VO}_{2}$ (A) is from the stack of $\mathrm{VO}_{2}$ (B) nanobelts. At high nucleation rate, $\mathrm{VO}_{2}(\mathrm{~B})$ prefers to aggregation rather than stacking, ${ }^{36,37}$ and thus no $\mathrm{VO}_{2}$ (A) appears. Hydrothermal reaction condition of $r=1$ (Fig. 2d) yields large hexagonal structure with ultra-long branches in the range of $4-8 \mu \mathrm{m}$ and $600 \mathrm{~nm}$ in width. The length decreases to $4-6 \mu \mathrm{m}(r=2)$ and 2-4 $\mu \mathrm{m}(r=3)$ respectively with increasing $\mathrm{H}_{2} \mathrm{C}_{2} \mathrm{O}_{4}$. $\mathrm{VO}_{6}$ octahedra of $\mathrm{VO}_{2}(\mathrm{~B})$ is different from $\mathrm{VO}_{2}$ (R), but similar to $\mathrm{VO}_{2}$ (A) (Fig. S2 $\dagger$ ). Thus, more energy is needed for the transformation from $\mathrm{VO}_{2}(\mathrm{~B})$ to $\mathrm{VO}_{2}(\mathrm{R})(r=2)$ than to $\mathrm{VO}_{2}(\mathrm{~A})(r=1)$. So an appropriate $\mathrm{H}_{2} \mathrm{C}_{2} \mathrm{O}_{4}$ could promote the formation of $\mathrm{VO}_{2}(\mathrm{R})$.

Fig. 6a shows the DSC curves of the as-synthesized $\mathrm{VO}_{2}(\mathrm{M})$ with $r$ of 1, 2 and 3. The DSC curves of both $r=1$ and 2 display endothermic and exothermic profiles upon heating and cooling in the temperature range of $0-100{ }^{\circ} \mathrm{C}$, indicating a reversible phase transition, ${ }^{38}$ but only an endothermic profile is observed in the heating process for $r$ of 3 . So the temperature range from -70 to $100{ }^{\circ} \mathrm{C}$ was adopted for the DSC measurement for $r$ of 3 , and the results are displayed in Fig. $6 \mathrm{~b}$. The phase transition temperature and hysteresis width of the samples are summarized in Fig. 6c. Apparently, the samples exhibit dramatically different phase transition properties. The $T_{\mathrm{C}}$ is $68,60.5$ and $62.5{ }^{\circ} \mathrm{C}$ during heating process, and 61.1, 137 and $-42{ }^{\circ} \mathrm{C}$ during cooling process. The hysteresis width is about $6.9,48.6$ and $104.5{ }^{\circ} \mathrm{C}$ for the as-synthesized $\mathrm{VO}_{2}(\mathrm{M})$ particles obtained at $r=1,2,3$, respectively, and the hysteresis width is not dependent on the particle size of micrometers. As shown in Fig. 7a, some residual $\mathrm{VO}_{2}(\mathrm{~A}), \mathrm{VO}_{2}(\mathrm{~B})$ and $\mathrm{VO}_{2}$ (D) phases exist



Fig. 5 Schematic evolution of the polymorph morphology. 

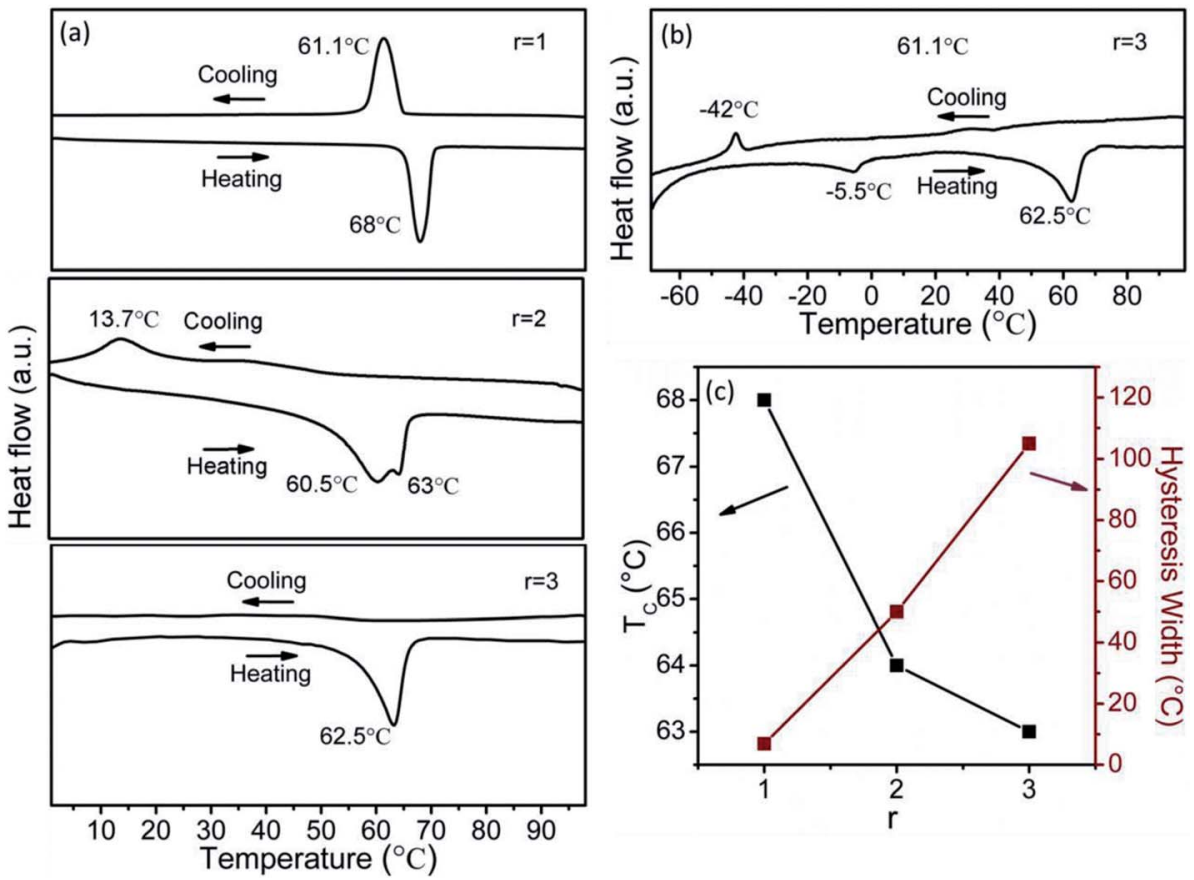

Fig. 6 (a and b) DSC curves of the as-prepared samples, (c) $T_{C}$ and hysteresis width.

except the dominating $\mathrm{VO}_{2}(\mathrm{M})$ phase at $r=1,2$ and 3 , respectively. The residual $\mathrm{VO}_{2}$ (A) has little effect on the phase transition of $\mathrm{VO}_{2}(\mathrm{M})$ obtained under $r=1$, as shown in Fig. 6c. On the contrary, the phase evolution of $\mathrm{VO}_{2}(\mathrm{M})$ obtained under $r=2,3$ is indeed a recrystallization process, and thus there is a considerable interaction between $\mathrm{VO}_{2}(\mathrm{~B})$ and $\mathrm{VO}_{2}(\mathrm{M})$ as well as between $\mathrm{VO}_{2}(\mathrm{D})$ and $\mathrm{VO}_{2}(\mathrm{M})$, so the residual $\mathrm{VO}_{2}(\mathrm{~B})$ and $\mathrm{VO}_{2}$ (D) affect the phase transition of $\mathrm{VO}_{2}(\mathrm{M})$ obtained under $r=2$ and 3. The transformation from monoclinic $(020)_{\mathrm{M}}$ plane at room temperature to $(200)_{\mathrm{R}}$ plane at high temperature was accompanied by the peak shift from $39.88^{\circ}$ to $39.67^{\circ}$. As shown in Fig. $7 b$, the peak of $(020)_{\mathrm{M}}$ plane shifts toward the smaller angle at $r=2$ and 3 . In addition, a new peak appears at $39.5^{\circ}$ for the sample prepared under $r=3$, and it is lower than $39.67^{\circ}$, implying increased $\mathrm{V}-\mathrm{V}$ bond length and stabilized $\mathrm{VO}_{2}(\mathrm{R})$ at room temperature. ${ }^{39}$ Therefore, more energy is needed to induce the phase transition in the cooling cycle, resulting in the large hysteresis width. Fig. 9a and b show the optical transmittance of the as-synthesized and annealed samples, respectively. All the samples show a sharp optical contrast in near infrared at 20 and $90{ }^{\circ} \mathrm{C}$. The $T_{\text {vis }}$ and $\Delta T_{2000}$ obtained from Fig. 9a and b are displayed in Fig. $9 \mathrm{c}$ and d, respectively. $T_{\text {vis }}$ changes a little but $\Delta T_{2000}$ increases significantly upon thermal annealing. It means that the residual phases affect the NIR modulation ability of $\mathrm{VO}_{2}(\mathrm{M})$ considerably.

It is difficult to obtain pure $\mathrm{VO}_{2}(\mathrm{M})$ in a $\mathrm{V}_{2} \mathrm{O}_{5}-\mathrm{H}_{2} \mathrm{C}_{2} \mathrm{O}_{4}$ reaction system if no thermal annealing or doping is done. ${ }^{37} \mathrm{As}$ shown in Fig. 8a, pure $\mathrm{VO}_{2}(\mathrm{M})$ is obtained after thermal annealing at $450{ }^{\circ} \mathrm{C}$ for $2 \mathrm{~h}$. The $T_{\mathrm{C}}$ is about $70.5,69.3$ and $68^{\circ} \mathrm{C}$ during the heating process, and $61.5,61.9$ and $62.1^{\circ} \mathrm{C}$ during cooling process (Fig. 8b), and the hysteresis width is about 9, 7.4 and $5.9^{\circ} \mathrm{C}$ when $r$ is 1,2 and 3, respectively. Apparently, the hysteresis widths of the samples prepared at $r=2,3$ are reduced dramatically upon thermal annealing. But the particle size and structure changes little [Fig. S5†], indicating high stability of the hexagonal $\mathrm{VO}_{2}(\mathrm{M})$. As stated above, the intermediate phases indeed have a great influence on the hysteresis width. In addition, the hysteresis width of the pure $\mathrm{VO}_{2}(\mathrm{M})$ obtained here is significantly smaller than what was reported. ${ }^{25,40}$ It can be due to the lattice distortions in coherent interface of adjacent branches. The defects act as nucleation site for metal-insulator transition and decrease the driving force. The number of branch grows as increasing $r$, as shown in Fig. 2, and the smallest hysteresis is obtained at $r$ of 3 .

Based on the preparation process in Fig. S6, $\uparrow$ the composite films are prepared to measure the optical properties. The suspension composed of $\mathrm{VO}_{2}(\mathrm{M})$ particles is uniformly cast on the PET substrate and the film exhibits a canary yellow color



Fig. 7 (a) XRD patterns of as-prepared samples with $r$ of 1-3, (b) magnified patterns. 

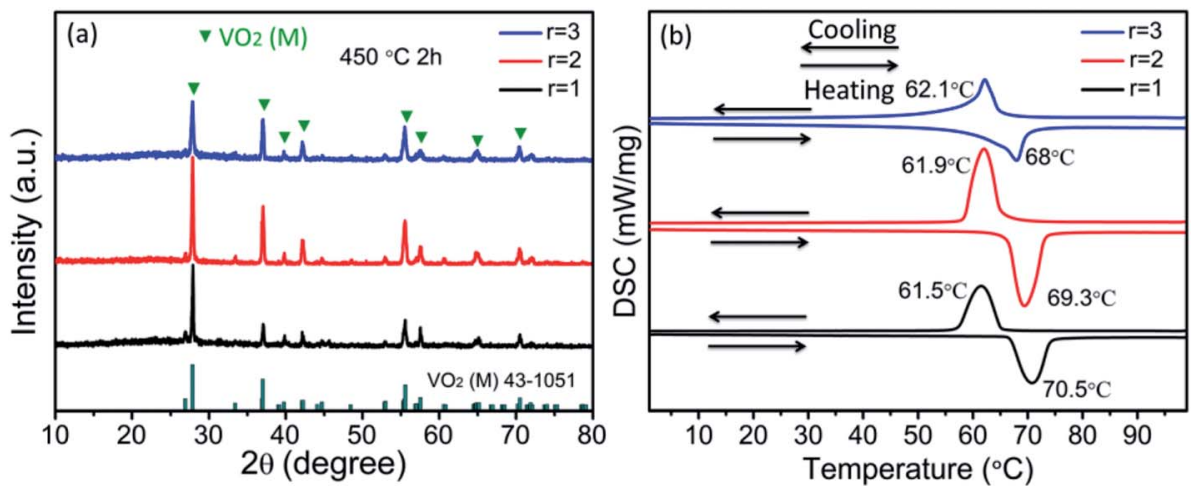

Fig. 8 (a) XRD patterns of the annealed samples (b) DSC curves of the annealed samples.

(Fig. S3b†). Fig. 9a and b show the optical transmittance of the samples before and after annealing, respectively. All the samples show a sharp optical contrast in near infrared at 20 and $90{ }^{\circ} \mathrm{C}$, indicating that the phase transition occurs. In addition, $\Delta T_{2000}$ is continuously improved from $28.3 \%$ to $41 \%$ as $r$ increases from 1 to 3 , due to the reduced sizes of the particles.

Tungsten (W) is the most effective dopant for reducing the phase transition temperature. Fig. 10a shows a wide-range survey X-ray photoelectron spectroscopy (XPS) of W-doped $\mathrm{VO}_{2}$ (M). $\mathrm{C}, \mathrm{V}, \mathrm{W}$ and $\mathrm{O}$ are detected, in which the signal of $\mathrm{C}$ is from the contamination on surface. From Fig. 10b, it can be seen that the $\mathrm{V}_{2 \mathrm{p} 3 / 2}$ peak of the particles is centered at $516.3 \mathrm{eV}$. As shown in Fig. 10c, the W4f orbital has the binding energies at 35.36 and $37.38 \mathrm{eV}$ corresponding to $\mathrm{W}_{4 \mathrm{ft} / 2}$ and $\mathrm{W}_{45 / 2 / 2}$, respectively. Accordingly, $\mathrm{W}$ in the powders is in the form of $\mathrm{W}^{6+}{ }^{41}$ It confirms that $\mathrm{W}$ atoms are actually doped into the $\mathrm{VO}_{2}$ nanoparticles. Fig. 10d shows the energy dispersive spectroscopy (EDS) of which $\mathrm{V}, \mathrm{O}, \mathrm{W}$ and $\mathrm{C}$ are involved. Fig. 11a shows the DSC curves of $\mathrm{W}_{x} \mathrm{~V}_{1-x} \mathrm{O}_{2}$ samples with different $\mathrm{W}$ concentrations. Each DSC curve displays sharp endothermic and exothermic profiles upon heating and cooling cycles. In addition, the double endothermic/ exothermic peaks appear during the heating/cooling process, probably due to the non-uniform doping or the polydispersity in the size distribution. ${ }^{42}$ As shown in Fig. 10b, $T_{\mathrm{C}}$ is reduced down to $28{ }^{\circ} \mathrm{C}$ and the hysteresis width is less than $10{ }^{\circ} \mathrm{C}$ when the doping level is 2.0 at $\%$. The substantially lowered transition temperature and small hysteresis width can meet the requirement for the applications in smart window completely. The hysteresis width is sensitive to the doping concentration. ${ }^{43}$ However, the doped samples with hexagonal structure are more stable with a hysteresis width changing from 5 to $8{ }^{\circ} \mathrm{C}$. In fact, the hexagonal porous morphology can provide a rigid framework and free volume simultaneously for the abrupt change between monoclinic and tetragonal phases.
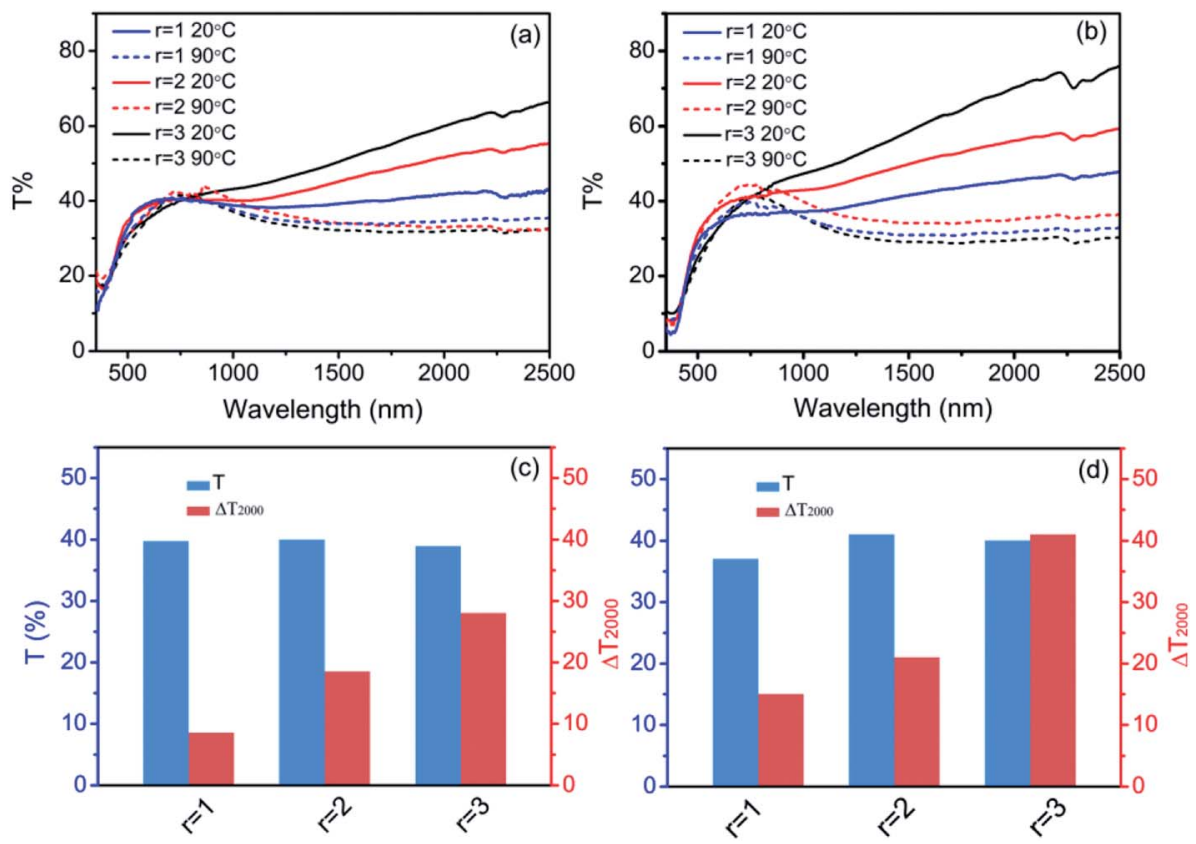

Fig. 9 Optical transmittance spectra of the (a) as-prepared and (b) annealed samples, (c and d) $T_{\text {vis }}$ and $\Delta T_{2000}$ of the as-prepared and annealed samples, respectively. 

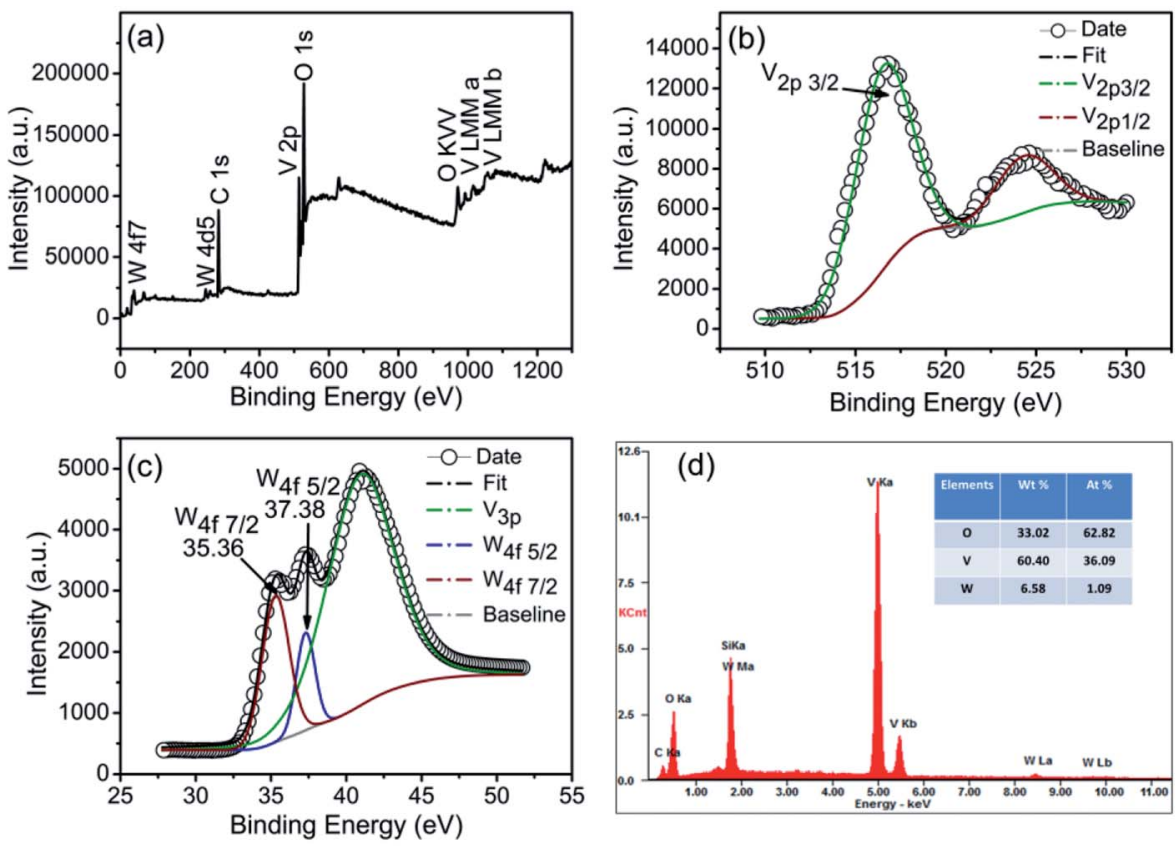

Fig. 10 (a) XPS spectra of $\mathrm{W}$-doped $\mathrm{VO}_{2}$, (b and c) high-resolution spectrum of V3p and W4f, respectively, (d) EDS spectra.
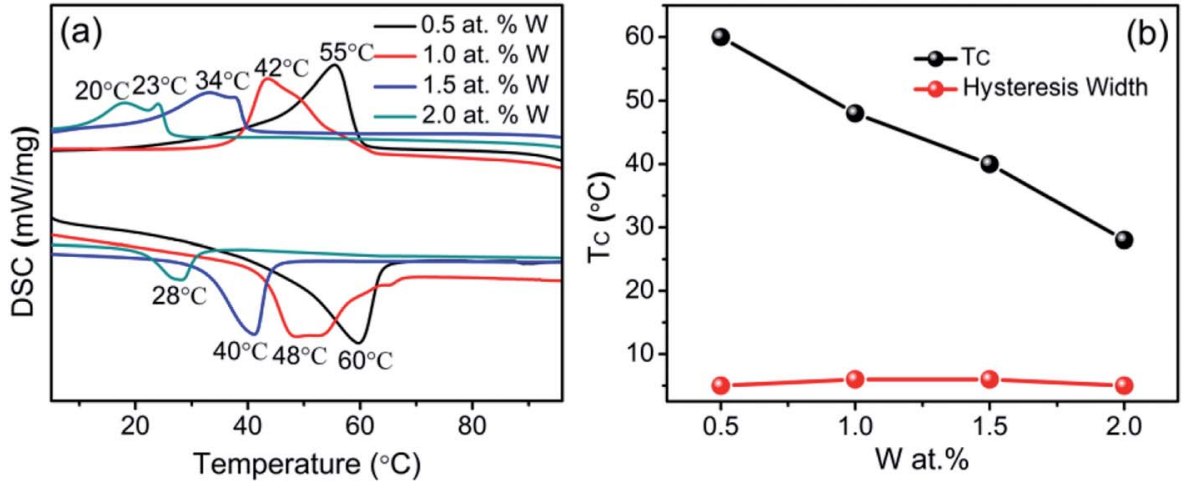

Fig. 11 (a) DSC curves of W-doped $\mathrm{VO}_{2}$, (b) phase transition temperature and hysteresis width as a function of W doping concentration.

\section{Conclusion}

In summary, $\mathrm{VO}_{2}(\mathrm{M})$ has been successfully synthesized through one-step hydrothermal method. $\mathrm{H}_{2} \mathrm{C}_{2} \mathrm{O}_{4}$ plays a role in adjusting the phases and dimension of $\mathrm{VO}_{2}$. This can be understood from the competition between the nucleation and growth rates. The coherent $\left((21 \overline{1})_{1} / /(2 \overline{1} \overline{1})_{2}\right)$ and $\left((2 \overline{1} \overline{1})_{1} / /(020)_{2}\right)$ interfaces between adjacent branches promote the formation of hexagonal structure. Furthermore, it is demonstrated that the $\mathrm{VO}_{2}(\mathrm{M})$ with hexagonal morphology improves the sensitivity and stability. The combination of hexagonal structure and $\mathrm{W}$ doping leads to substantially reduced phase transition temperature down to $28{ }^{\circ} \mathrm{C}$.

\section{Conflicts of interest}

There are no conflicts to declare.

\section{Acknowledgements}

This work was jointly supported by National Natural Science Foundation of China (Grant No. 51771144, 51471130), Natural Science Foundation of Shaanxi Province (No. 2017JZ015), the fund of the State Key Laboratory of Solidification Processing in NWPU (SKLSP201708), Fundamental Research Funds for the Central Universities, City University of Hong Kong Applied Research Grant (ARG) No. 9667104.

\section{References}

1 J. Liu, Q. Li, T. Wang, D. Yu and Y. Li, Angew. Chem., 2004, 116, 5158-5162.

2 T. Y. Y. Oka, S. Sato and N. Yamamoto, J. Solid State Chem., 1998, 140, 219. 
3 L. L. B. Y. Qu, Y. Xie and B. C. Pan, Phys. Lett. A, 2011, 375, 3474.

4 J. M. C. J. H. Park, T. S. Kasirga, C. Huang, Z. Fei, S. Hunter and D. H. Cobden, Nature, 2013, 500, 431-434.

5 S. A. Corr, M. Grossman, Y. Shi, K. R. Heier, G. D. Stucky and R. Seshadri, J. Mater. Chem., 2009, 19, 4362.

6 G. Nie, L. Zhang, J. Lei, L. Yang, Z. Zhang, X. Lu and C. Wang, J. Mater. Chem. A, 2014, 2, 2910.

7 Y. Gao, H. Luo, Z. Zhang, L. Kang, Z. Chen, J. Du, M. Kanehira and C. Cao, Nano Energy, 2012, 1, 221-246.

8 Q. G. J. Wu, B. S. Guiton, N. P. de Leon, L. Ouyang and H. Park, Nano Lett., 2006, 6, 2313-2317.

9 B. Hu, Y. Ding, W. Chen, D. Kulkarni, Y. Shen, V. V. Tsukruk and Z. L. Wang, Adv. Mater., 2010, 22, 5134-5139.

10 B. Hu, Y. Zhang, W. Chen, C. Xu and Z. L. Wang, Adv. Mater., 2011, 23, 3536-3541.

11 S. Sengupta, K. Wang, K. Liu, A. K. Bhat, S. Dhara, J. Wu and M. M. Deshmukh, Appl. Phys. Lett., 2011, 99, 062114.

12 B. Sipos, M. Duchamp, A. Magrez, L. Forró, N. Barišić, A. Kis, J. W. Seo, F. Bieri, F. Krumeich, R. Nesper and G. R. Patzke, J. Appl. Phys., 2009, 105, 074317.

13 R. Xie, C. T. Bui, B. Varghese, Q. Zhang, C. H. Sow, B. Li and J. T. L. Thong, Adv. Funct. Mater., 2011, 21, 1602-1607.

14 N. Wang, S. Magdassi, D. Mandler and Y. Long, Thin Solid Films, 2013, 534, 594-598.

15 J. Zheng, S. Bao and P. Jin, Nano Energy, 2015, 11, 136-145.

16 C. Liu, X. Cao, A. Kamyshny, J. Y. Law, S. Magdassi and Y. Long, J. Colloid Interface Sci., 2014, 427, 49-53.

17 W. Ning, H. Yizhong, S. Magdassi, D. Mandler, L. Hai and L. Yi, RSC Adv., 2013, 3, 7124.

18 K. Martens, I. P. Radu, S. Mertens, X. Shi, L. Nyns, S. Cosemans, P. Favia, H. Bender, T. Conard, M. Schaekers, S. De Gendt, V. Afanas'ev, J. A. Kittl, M. Heyns and M. Jurczak, J. Appl. Phys., 2012, 112, 124501.

19 J. Wu, W. Huang, Q. Shi, J. Cai, D. Zhao, Y. Zhang and J. Yan, Appl. Surf. Sci., 2013, 268, 556-560.

20 S. N. P. Jin and S. Tanemura, Thin Solid Films, 1998, 324, 151.

21 D. Vernardou, D. Louloudakis, E. Spanakis, N. Katsarakis and E. Koudoumas, Sol. Energy Mater. Sol. Cells, 2014, 128, 36-40.

22 J. Sakai, M. Zaghrioui, V. Ta Phuoc, S. Roger, C. AutretLambert and K. Okimura, J. Appl. Phys., 2013, 113, 123503.
23 Y. Gao, C. Cao, L. Dai, H. Luo, M. Kanehira, Y. Ding and Z. L. Wang, Energy Environ. Sci., 2012, 5, 8708.

24 J. Zhang, J. Li, P. Chen, F. Rehman, Y. Jiang, M. Cao, Y. Zhao and H. Jin, Sci. Rep., 2016, 6, 27898.

25 Y. F. G. Z. Chen, L. T. Kang, C. X. Cao, S. Chen and H. J. Luo, J. Mater. Chem. A, 2014, 2, 2718.

26 W. Yu, S. Li and C. Huang, RSC Adv., 2016, 6, 7113-7120.

27 Y. G. C. Cao and H. Luo, J. Phys. Chem. C, 2008, 112, 1881018814.

28 J. Galy, J. Solid State Chem., 1999, 148, 224-228.

29 G. N. C. Leroux and G. Van Tendeloo, Phys. Rev. B: Condens. Matter Mater. Phys., 1998, 57, 5111.

30 M. Li, D.-B. Li, J. Pan, J.-C. Lin and G.-H. Li, Eur. J. Inorg. Chem., 2013, 2013, 1207-1212.

31 M. Li, S. Magdassi, Y. Gao and Y. Long, Small, 2017, 13, 1701147.

32 C. Cao, Y. Gao and H. Luo, J. Phys. Chem. C, 2008, 112, 18810-18814.

33 S. Ji, F. Zhang and P. Jin, J. Solid State Chem., 2011, 184, 2285-2292.

34 L. Dai, Y. Gao, C. Cao, Z. Chen, H. Luo, M. Kanehira, J. Jin and Y. Liu, RSC Adv., 2012, 2, 5265.

35 M. Li, F. Kong, Y. Zhang and G. Li, CrystEngComm, 2011, 13, 2204.

36 Z. Liu, M. Miyauchi, T. Yamazaki and Y. Shen, Sens. Actuators, B, 2009, 140, 514-519.

37 J. F. L. J. T. Zhang, Q. Peng, X. Wang and Y. D. Li, Chem. Mater., 2006, 18, 867-871.

38 M. J. Powell, P. Marchand, C. J. Denis, J. C. Bear, J. A. Darr and I. P. Parkin, Nanoscale, 2015, 7, 18686-18693.

39 Y. Cui, S. Shi, L. Chen, H. Luo and Y. Gao, Phys. Chem. Chem. Phys., 2015, 17, 20998-21004.

40 J. Zhu, Y. Zhou, B. Wang, J. Zheng, S. Ji, H. Yao, H. Luo and P. Jin, ACS Appl. Mater. Interfaces, 2015, 7, 27796-27803.

41 G. X. X. Liu, C. Huang, Q. Xu, Y. Zhang and Y. Luo, Mater. Lett., 2008, 62, 1878-1880.

42 C. J. Patridge, L. Whittaker, B. Ravel and S. Banerjee, J. Phys. Chem. C, 2012, 116, 3728-3736.

43 Y. Zhang, J. Zhang, X. Zhang, S. Mo, W. Wu, F. Niu, Y. Zhong, X. Liu, C. Huang and X. Liu, J. Alloys Compd., 2013, 570, 104113. 